\title{
Recent articles
}

\section{JULY 2008}

Employment of foreign workers in the UK: 1997 to 2008

Gareth Clancy

Regional analysis of public sector employment Andrew Barnard

The effects of taxes and benefits on household income, 2006/07

Francis Jones

Dealing with potential bias in early estimates of GDP

Robin Youll

Recent trends in corporate net lending

Graeme Chamberlin

Measuring inflation

Rob Pike

Services producer price index (experimental) - first quarter 2008 lan Richardson

\section{AUGUST 2008}

Modelling the gender pay gap in the UK: 1998 to 2006

Andrew Barnard

Inventories: a cross-country comparison of behaviour and methodology Barry Williams

Regional gross disposable household income

Eddie Holmes

SIC 2007: implementation in ONS

John C Hughes

Measuring the quality of the producer price index - an update Joanna Woods

Regional economic indicators, August 2008, with a focus on household income Birgit Wosnitza and Martin Walker

\section{SEPTEMBER 2008}

Measuring UK inflation

Rob Pike, Catherine Marks and Darren Morgan

Command GDP: the purchasing power of UK output

Graeme Chamberlin

The impact of the 2006 National Minimum Wage rise on employment lan Mulheirn

The preliminary R\&D satellite account for the UK: a sensitivity analysis Peter Evans, Michael Hatcher and Damian Whittard

Job separations in the UK

Katherine Kent

Methods explained: perpetual inventory method Sumit Dey-Chowdhury

\section{OCTOBER 2008}

Measuring the UK economy 2008: the National Statistician's perspective Karen Dunnell

The effect of bonuses on earnings growth in 2008 Harry Duff

Overview of UK National Accounts and Balance of Payments: Blue Book and Pink Book 2008

Ross Meader and Geoff Tily

Annual Population Survey household data sets

Kathryn Ashton and Katherine Kent

Supply-side estimates of UK investment Graeme Chamberlin

Services producer price index (experimental) - second quarter 2008 lan Richardson

\section{NOVEMBER 2008}

Sickness absence from work in the UK Debra Leaker

Analysis of international trade and productivity, using the EUKLEMS database Peter Goodridge

Producer price index rebasing to $2005=100$

Rob Luckwell

Labour Force Survey: interim reweighting 2008

Nick Palmer and Mark Chandler

Experimental estimates of rural-urban productivity Sumit Dey-Chowdhury and Pippa Gibson

Regional economic indicators, November 2008, with a focus on skills Birgit Wosnitza, Peggy Causer and Jonathan Knight

\section{DECEMBER 2008}

The distribution of household income 1977 to 2006/07

Francis Jones, Daniel Annan and Saef Shah

Making sense of Labour Force Survey response rates William Barnes, Geoff Bright and Colin Hewat

How similar are ONS's annual and monthly business inquiries? Joe Robjohns and Damian Whittard

Introducing the new business demography statistics Karen Grierson and Andrew Allen

The impact of Labour Force Survey and Annual Population Survey reweighting Marilyn Thomas and Sally-Ann Aubrey-Smith

Rebasing the services producer price index Terry Bradley

Methods explained: cost-benefit analysis Barry Williams

\section{Future articles}

List is provisional and subject to change.

\section{FEBRUARY 2009}

Special Labour Market Review edition

The Labour Market and Wider Economy

Labour Demand

Labour Supply - Employment

Labour Supply - Unemployment

Labour Supply - Inactivity

Labour Costs 